\title{
Genital piercing and beading; threat to life?
}

\author{
L D S U Senaratne, N I C Perera, G A Ratnatilaka
}

Ceylon Medical Journal 2014; 59: 106

The history of genital piercing and modification goes back to ancient times, practiced for reasons varying from tradition and machismo to increased sexual pleasure. Genital beading was practiced initially by the Yakuza in Japan [1].

A 33-years old Indonesian fisherman was admitted to National Hospital of Sri Lanka, with difficulty in opening his mouth and severe myalgia for 3 days. Examination revealed severe trismus and neck spasms. Language barrier resulted in difficulty in taking a detailed history. Tetanus, sea snake bite or ingestion of a poisonous fish were the differential diagnoses. Tetanus antisera and tetanus toxoid were administered. Next day metal penile rings and subcutaneous penile beads were found during urinary catheterisation. Revised history indicated that the metal rings seen on the ventral surface of the penis (Figure.1) had been purchased from Pettah (Colombo), Sri Lanka and inserted while on the ship, using shark teeth to pierce the skin. The penile beads were whale teeth inserted similarly underneath the skin of penis, ten days prior to onset of symptoms. He developed generalised spasms and a clinical diagnosis of tetanus was confirmed. Elective tracheostomy was done and the rings and beads removed surgically. The patient recovered after 30 days in the intensive care unit.

Complications of body piercing include allergies, infections (hepatitis and HIV), keloid scars, foreign body rejection and abscess formation [2,3]. Here we report a case of tetanus following unhygienic piercing of the genitalia. Since body piercing is becoming popular, doctors should be aware that the incidence of tetanus may increase in future. Health authorities should monitor salons providing such services for sterility.



Figure 1.

\section{References}

1. Nguyen DP, Desai BK, Falgiani M. Visual Diagnosis: Pearling - a case study. International Journal of Emergency Medicine 2011; 4: 74.

2. Meltzer DI. Complications of body piercing. American Family Physician 2005; 72: 2029-34.

3. Laumann A, Derick A. Tattoos and body piercings in United States: A national data set. Journal of American Academy of Dermatology 2006; 55: 413-21.

Medical Unit, National Hospital of Sri Lanka.

Correspondence: LDSU, e-mail: <sewwandisenaratne@yahoo.com>. Received 20 March and revised version accepted 26 July 2014. Competing interests: none declared. 